\title{
Journal Bearings Lubrication Aspect Analysis Using Non-Newtonian Fluids
}

\author{
Abdessamed Nessil, Salah Larbi, Hacene Belhaneche, and Maamar Malki \\ Laboratory of Mechanical Engineering and Development, Department of Mechanical Engineering, \\ Polytechnic National School of Algiers, 10 Avenue Hassen Badi, El-Harrach, Algiers, Algeria \\ Correspondence should be addressed to Salah Larbi; larbisalah@yahoo.fr
}

Received 30 August 2012; Revised 14 December 2012; Accepted 29 December 2012

Academic Editor: Michel Fillon

Copyright (C) 2013 Abdessamed Nessil et al. This is an open access article distributed under the Creative Commons Attribution License, which permits unrestricted use, distribution, and reproduction in any medium, provided the original work is properly cited.

\begin{abstract}
The aim of this work is related to an analysis of journal bearings lubrication using non-Newtonian fluids which are described by a power-law model. The performance characteristics of the journal bearings are determined for various values of the non-Newtonian power-law index " $n$ " which is equal to: $0.9,1$, and 1.1. Obtained numerical results show that for the dilatant fluids $(n>1)$, the load-carrying capacity, the pressure, the temperature, and the frictional force increased while for the pseudo-plastic fluids $(n<1)$ they decreased. The influence of the thermal effects on these characteristics is important at higher values of the flow behavior index " $n$." Obtained results are compared to those obtained by others. Good agreement is observed between the different results.
\end{abstract}

\section{Introduction}

The evolution of machines with severe operating conditions, following to the number of revolutions increasingly high and shafts strongly charged, has a consequence on energy dissipation in the lubricating film by shearing. The dissipated energy induces an increase in the fluid film temperature, a reduction of the lubricant fluid viscosity and the bearing pressure of the mechanism, and a premature wear of the material used. The isothermal theory of lubrication is widely used in the performances determination of the butted and hydrodynamic bearings. However, the technological requirements, such as the increase in loads and the number of revolutions per hours, generate important dissipation of energy in the lubricated mechanisms [1].

The classical theory of lubrication developed by O. Reynolds for isothermal cases is improved by Kingsbury [2] by taking into account the heat transfer phenomena and by assuming the fluid used as viscous and Newtonian. However, in most mechanisms encountered in real situations, nonNewtonian fluids are used in order to increase the lubricants viscosity index by adding additives such as polymers [3]. The first approach modelling of the thermal aspect of lubrication was proposed by Kingsbury, in order to take into account the temperature evolution through the thickness of the film. The method of resolution applied to the conical sleeve viscometer case is a graphic method. In his study, Kingsbury has showed that the shearing stress of the bearing surface is about $40 \%$ of the constraint value calculated by using the isothermal theory. It can be deduced easily whereas the heating of the film causes a reduction of the load supported by the shaft of $60 \%$ compared to the load calculated by the isothermal theory for similar operating conditions.

The behaviour's law of non-Newtonian fluids is nonlinear, which has a consequence on the nonvalidity of Reynolds equations commonly used in the traditional hydrodynamic lubrication. The non-Newtonian lubricants are encountered in various processes of lubrication. During the four last decades, the interest to lubrication problems using nonNewtonian fluids behaviour became extensive [4-6].

Williams and Symmons [7] presented a technique for solving the Navier-Stokes equations for steady state, threedimensional flow of a non-Newtonian fluid within a finitebreadth hydrodynamic journal bearing. In another paper [8] the authors solved the governing equations by using a finite difference approach together with a semi-implicit method for pressure-linked equations and for a non-Newtonian fluid case within a finite width slider thrust bearing.

Adiabatic solutions for a finite width hydrodynamic journal bearing with non-Newtonian lubricants were presented 
by Jang and Chang [9]. The authors illustrated that the loadcarrying capacity may be greatly reduced to one-third of its value when compared with that given by the isothermal solutions.

Tsann-Rong and Jen-Fin [10] presented a numerical study of compressible elastohydrodynamic lubrication using power-law fluids. The performance characteristics are investigated for the power-law index $n$ in the range from 0.8 to 1.2. The numerical results illustrated that, with increase in the power-law index $n$, the pressure spike moves toward the centre of contact and the location of the cavitation moves away from the centre of contact.

Sheau-Ming and Cheng-I [11] analysed the thermohydrodynamic aspect of a finite width hydrodynamic journal bearing using non-Newtonian lubricants obeying the powerlaw model. The modified Reynolds equation is solved numerically by using Elrod algorithm. The authors showed that the thermal effects are more pronounced at higher values of flow behaviour index $n$, eccentricity, and slenderness ratios.

Hlaváček [12] developed the Reynolds equation for lubrication of rigid cylinders with soft incompressible coatings and a non-Newtonian piecewise power-law lubricant in the rolling motion. He concluded that the effect of increased viscosity of the normal synovial fluid for low shear rates does not influence the fluid film thickness for entraining velocities encountered.

Kim and Seireg [13] developed a mathematical model to study the influence of the rheological properties of the lubricant on the thermohydrodynamic aspect analysis of the lubricant film occurring in slider and journal bearings. Obtained results showed that the shear zone thickness is significantly smaller than the fluid film thickness in the lubrication zone.

The thermohydrodynamic aspect of journal bearings, extended to include couple stress effects in lubricants blended with high polymer additives, is analysed by Wang et al. [14]. The results showed that lubricants with couple stresses, compared with Newtonian lubricants, not only yield an increase in load capacity and decrease in friction coefficient, but also produce a lower bearing temperature field.

Manglik and Fang [15] analysed numerically the forced convective heat transfer phenomena in fully developed laminar flows of power-law fluids in eccentric annular ducts. Numerical solutions were presented relating to velocity and temperature distributions, isothermal frictions factors, and Nusselt numbers for annular ducts of varying aspect ratios and inner core eccentricity for both shear-thinning and shear-thickening fluids. Obtained results showed that owing to geometric asymmetry of the eccentric annular crosssection, the flow tends to stagnate in the narrow section and have higher peak velocities in the wide section which induces greater nonuniformity in the temperature field, and degradation in the average heat transfer coefficient.

Fantino and Bou-Saïd [16] in their study on inertia, shear-thinning and thermal effects on connecting rod bearing behaviour, showed the strong influence of the housing deformations as well as the shape defects in the connecting rod bearings performances.

In order to predict the influence of non-Newtonian behaviour of incompressible lubricants on the hydrodynamic thrust bearings, Bouyahia et al. [17] developed a numerical study using rheological models related to the power law, the Bingham, and the Herschel-Bulkley formulas. The load capacity, friction torque, and power loss were calculated according to their importance from an industrial point of view.

Wang and Zhu [18] developed a numerical study for a finite journal bearing lubricated with micropolar fluids by considering both thermal and cavitating effects. The modified Reynolds equation and energy equation are derived based on Eringen's micropolar fluid theory. The Elrod's cavitation algorithm is used to determine the solution of the modified Reynolds equations. The effects of the size of material characteristic length and the coupling number on the thermohydrodynamic performance of a journal bearing are investigated. It is shown that micropolar fluids exhibit the increase in load capacity and temperature compared with Newtonian fluids.

Wei et al. [19] proposed a mathematical model including the Reynolds equation, the particle load carrying equation, the asperity contact equation, and the heat balance equation in order to simulate the mixed liquid-solid lubrication. The effects of the mixed liquid-solid lubricant, the particle diameter and mass concentration, the surface composite roughness, and the material properties were discussed. Obtained results by the mathematical model developed are in agreement with the practical mixed liquid-solid lubrication.

Garg et al. [20] investigated the thermal and rheological effects of lubricant on the performance of the slot-entry hybrid journal bearing system. FEM was used to solve the governing equations. The computed results showed that the viscosity's variation due to the temperature rise and nonNewtonian behaviour of lubricant affects the bearing performance.

Jaw-Ren et al. [21] presented micropolar fluids analysis on the dynamic stiffness and damping characteristics of parabolic-film slider bearings. The authors concluded that the non-Newtonian effects of micropolar fluids provide higher load capacities and higher dynamic coefficients, comparing with the Newtonian lubricants case.

The work presented in this paper is related to the journal bearings lubrication aspect analysis using non-Newtonian fluids which are described by a power law formula and by taking into account the thermohydrodynamic aspect of the problem. The influence of the various values of the nonNewtonian power-law index, $n$, on the lubricant film (temperature, pressure) and the journal bearing properties are also analysed by using the Reynolds equation in its generalized form.

\section{Physical and Mathematical Models}

2.1. Physical Model. Figure 1 gives a schematic representation of a journal bearing system. It consists of a bearing with a centre $O_{B}$ and a radius $R_{B}$, and a shaft with a centre $O_{S}$ and a radius $R_{S}$. Under the load action, the centres $O_{B}$ and $O_{S}$ do not coincide. The distance $O_{B} O_{S}$ is called the absolute eccentricity. If the axes of the bearing and the shaft are parallel, and if we neglect the elastic strain of surfaces, under the effect of the temperature and the pressure, these two parameters are sufficient to locate the position of the shaft 

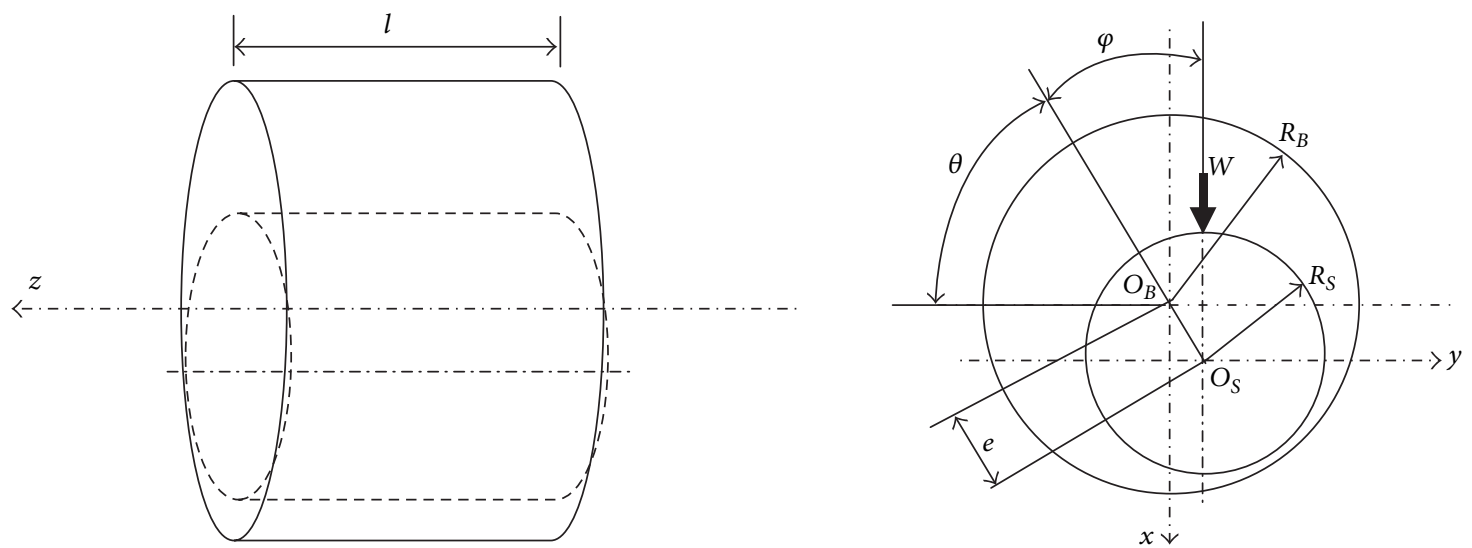

FIGURE 1: Schematic representation of a journal bearing.

inside the bearing. The radius $R_{B}$ is approximately equal to $R_{S}$ in the contact zone, between the bearing and the shaft, and then we can neglect the curve shape of the film, develop the bearing, and compare it to a plan shape.

2.2. Mathematical Model. The mathematical modelling of the problem is based on conductive heat transfer equations, for the bearing and the shaft, and on energy and momentum equations, formulated by Reynolds equation, for the lubricating film.

The generalized Reynolds equation is given by [10]

$$
\frac{\partial}{\partial x}\left[G \frac{\partial p}{\partial x}\right]+\frac{\partial}{\partial z}\left[G \frac{\partial p}{\partial z}\right]=U \frac{\partial}{\partial x}\left[h-\frac{I_{2}}{J_{2}}\right],
$$

where

$$
\begin{aligned}
& I_{2}=\int_{0}^{h} \frac{y}{\mu_{a}} d y, \quad J_{2}=\int_{0}^{h} \frac{d y}{\mu_{a}}, \quad R=\int_{0}^{y} \rho(x, \xi, z, t) d \xi, \\
& F=\frac{1}{J_{2}} \int_{0}^{h} \frac{R}{\mu_{a}} d y, \quad G=\int_{0}^{h} \frac{R y}{\mu_{a}} d y-I_{2}, F, \\
& U=\omega R_{S} .
\end{aligned}
$$

The thickness of the film, $h$, is (see Figure 1)

$$
h=C(1+\varepsilon \cos \theta)
$$

with

$$
C=\left(R_{B}-R_{S}\right), \quad \varepsilon=\frac{e}{C}, \quad \theta=\frac{x}{R_{S}} .
$$

In Cartesian coordinates system, balance energy equation in lubricating film is given by

$$
\begin{aligned}
& \rho \cdot C_{P} {\left[u \frac{\partial T}{\partial x}+v \frac{\partial T}{\partial y}+w \frac{\partial T}{\partial z}\right] } \\
&=K \frac{\partial^{2} T}{\partial y^{2}}+\mu_{a}\left[\left(\frac{\partial u}{\partial y}\right)^{2}+\left(\frac{\partial w}{\partial y}\right)^{2}\right] .
\end{aligned}
$$

Within the bearing, the thermal phenomena are governed by the conductive heat equation given by

$$
\rho C \frac{\partial T}{\partial t}=K \Delta T
$$

Taking into account the cylindrical shape of the bearing, the above equation will then be

$$
\rho \cdot C \frac{\partial T}{\partial t}=K\left[\frac{1}{r} \frac{\partial}{\partial r}\left(\frac{\partial T}{\partial r}\right)+\frac{1}{r^{2}} \frac{\partial^{2} T}{\partial r^{2}}+\frac{\partial^{2} T}{\partial z^{2}}\right] .
$$

The heat transfer process in the shaft is governed by the equation of energy at steady state. According to experimental results [1], the temperature of the fast revolving shaft is independent of the angular coordinate $\theta$. Under these conditions, the heat equation is written $[10]$ as

$$
\frac{1}{r} \frac{\partial}{\partial r}\left(\frac{\partial T}{\partial r}\right)+\frac{1}{r^{2}} \frac{\partial^{2} T}{\partial r^{2}}+\frac{\partial^{2} T}{\partial z^{2}}=0 .
$$

2.3. Boundary Conditions. The boundary conditions used for the film are those of Swift-Stieber [10]. They take into account the conservation of the flow at the rupture of film, and they are expressed by the pressure conditions as follows:

$$
P\left(\theta_{s}, z\right)=0, \quad \frac{\partial P}{\partial \theta}\left(\theta_{s}, z\right)=0 .
$$

About the bearing, the boundary condition is given by the continuity of flow between ambient air and the external surface of the bearing. It is given by

$$
-\left.K_{B} \frac{\partial T}{\partial r}\right|_{r=R_{B}}=h_{B}\left[\left.T\right|_{r=R_{B}}-T_{A}\right] .
$$

The interface condition, between the lubricant and the internal surface of the bearing, is given by the below condition:

$$
\left.K_{F} \frac{\partial T}{\partial y}\right|_{y=0}=-\left.K_{B} \frac{\partial T}{\partial r}\right|_{r=R_{B}} .
$$

For the shaft-film condition, because the shaft is fast in rotation, this flow is independent of the angular co-ordinate, thus we integrate the heat flow leaving the film on a crown of a radius equal to the radius of the shaft and with a width, $d z$. Then, it is given as follows:

$$
\left.K_{s} \frac{\partial T}{\partial r}\right|_{r=R_{s}} 2 \pi R_{s} d z=-\left.K_{F} d z \int_{0}^{2 \pi} \frac{\partial T}{\partial y}\right|_{y=h} R_{S} d \theta .
$$


The boundary condition between the shaft and the film fluid is given by the continuity of heat flow at the interface. It is given by

$$
-\left.K_{S} \frac{\partial T}{\partial z}\right|_{z=0, l}=h_{S}\left[\left.T\right|_{z=0, l}-T_{A}\right] .
$$

The law of the lubricating oil viscosity used is given by [7]

$$
\mu_{a}=m(t) \cdot\left[\left(\frac{\partial u}{\partial y}\right)^{2}+\left(\frac{\partial w}{\partial y}\right)^{2}\right]^{(n-1) / 2},
$$

with

$$
m(t)=m_{0} \cdot \exp \left(\beta_{f} \cdot\left(T-T_{0}\right)\right)
$$

\section{Numerical Procedure}

The solution of the problem requires the resolution of (1)-(8) with the boundary conditions (9)-(13). The partial differential equations governing the fluid flow, heat transfer, and energy are interlinked via the viscosity-temperature dependence. These equations are discretized using a centered finite difference scheme [22]. The domain of study is divided into 51 nodes along the circumferential direction, 51 nodes along the radial direction, and 21 nodes along the axial direction. Firstly, the viscosity value is initialized. The pressure distribution and attitude angle are calculated iteratively. The generalized Reynolds equations are solved numerically using Gauss-Seidel method with an over relaxation factor equals to 1.8 . The iterative procedure is stopped when the relative difference in the pressure field and attitude angle between two excessive iterations falls below $0.01 \%$. Once the pressure field converges, the velocities components and their derivatives terms are then evaluated. The energy and heat flow equations are solved simultaneously with a relaxation factor equals to 0.8 , and the boundary conditions are incorporated into the iterative system. The corresponding convergence criterion is $\left|\left(T^{\text {new }}-T^{\text {old }}\right) / T^{\text {old }}\right| \leq 10^{-4}$. When the temperature parameter converges, the viscosity is updated according to (14), with the convergence criterion: $\left|\left(\mu^{\text {new }}-\mu^{\text {old }}\right) / \mu^{\text {old }}\right| \leq 10^{-3}$.

\section{Results and Discussion}

The journal bearing used is that of [11]. It has two components, one representing the shaft and the other the bearing, the system is supplied by lubricant fluid through openings, which emerge in an axial groove. The experimental data used are given by Table 1 .

Figure 2 shows the evolution of the pressure in the film, according to the circumferential coordinate, and for various values of index of structure $n$, where we can note that the pressure increases with the increase of this index. The use of the dilatant fluids gives an increase in the pressure of load, which reaches up to $122 \%$ the value obtained by using Newtonian fluids for the same operating conditions.

Figure 3 gives the pressure evolution in the film versus the circumferential coordinate, for different values of structure's index $n$, and for two different cases (thermohydrodynamic and isotherm). The variation of the pressure between the isothermal and the thermohydrodynamic cases increases
TABLE 1: Technical data used for the numerical simulation.

\begin{tabular}{lc}
\hline Journal bearing length & $l=10^{-1} \mathrm{~m}$ \\
Shaft radius & $R_{S}=0.05 \mathrm{~m}$ \\
External bearing radius & $R_{B}=10^{-1} \mathrm{~m}$ \\
Radial clearance & $C=10^{-4} \mathrm{~m}$ \\
Ambient temperature & $T_{A}=40^{\circ} \mathrm{C}$ \\
Initial temperature of lubrication & $T_{\mathrm{al}}=36.8^{\circ} \mathrm{C}$ \\
Coefficient of (15) & $m_{0}=0.0323 \mathrm{~Pa} \cdot \mathrm{s}$ \\
Coefficient of (15) & $\beta_{f}=0.037^{\circ} \mathrm{C}^{-1}$ \\
Initial pressure of lubrication & $\mathrm{Pa}=70.10^{3} \mathrm{~Pa}$ \\
Lubricant density & $\rho=860 \mathrm{~kg} / \mathrm{m}^{3}$ \\
Lubricant specific heat & $C_{p}=2000 \mathrm{~J} / \mathrm{kg} \cdot \mathrm{K}$ \\
Bearing thermal conductivity & $K_{B}=50.84 \mathrm{~W} / \mathrm{m} \cdot \mathrm{K}$ \\
Shaft thermal conductivity & $K_{S}=52.0 \mathrm{~W} / \mathrm{m} \cdot \mathrm{K}$ \\
Film thermal conductivity & $K_{F}=0.13 \mathrm{~W} / \mathrm{m} \cdot \mathrm{K}$ \\
Bearing convective heat transfer coefficient & $h_{B}=80 \mathrm{~W} / \mathrm{m}^{2} \cdot \mathrm{K}$ \\
Shaft convective heat transfer coefficient & $h_{S}=100 \mathrm{~W} / \mathrm{m}^{2} \cdot \mathrm{K}$ \\
Revolution speed & $N=2000 \mathrm{rev} \cdot / \mathrm{min}$ \\
\hline
\end{tabular}

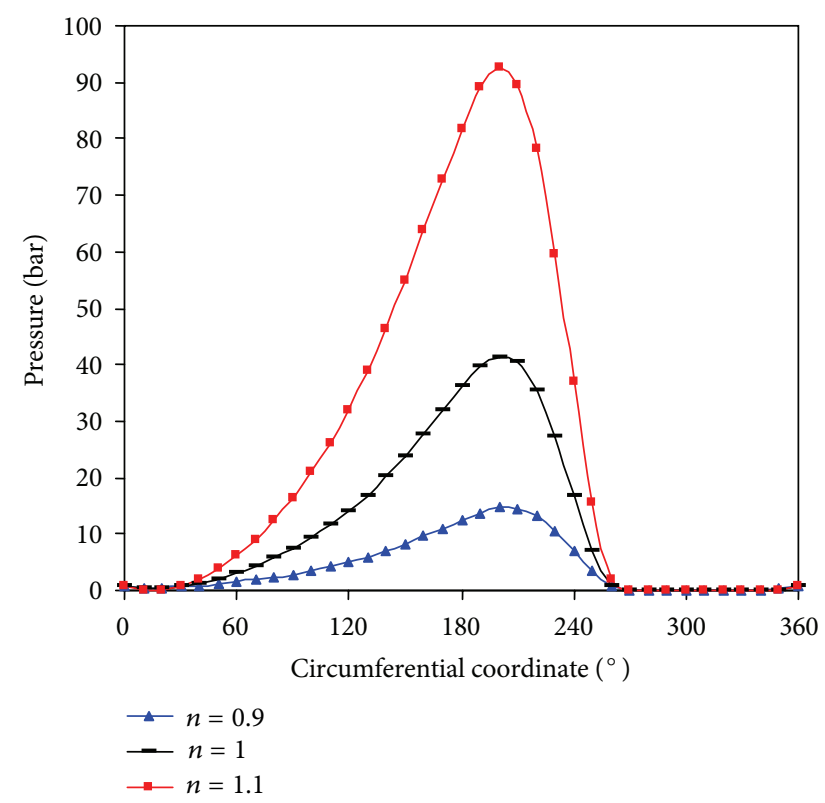

FIGURE 2: Pressure distributions versus the circumferential coordinate at the central plan of the journal bearing for different values of $n$ index.

with the increase of the index of structure. We can also note that the heating effect is more important for the dilatant fluids, where the variation of the results between the two cases, isothermal and thermohydrodynamic, is very large (reached up to $116 \%$ ), that is justify the importance of the thermohydrodynamic aspect to analysis in the case of such fluids. However, for the pseudoplastic fluids, the variation is very weak; the thermohydrodynamic aspect has not a great influence.

Figures 4, 5, 6, 7, 8, and 9 show the influence of the revolution number by minute and the structure index on the isothermal lines of the journal bearing. We note that the revolution number by minute has a slight influence on the isothermal lines for small values of the structure index. 


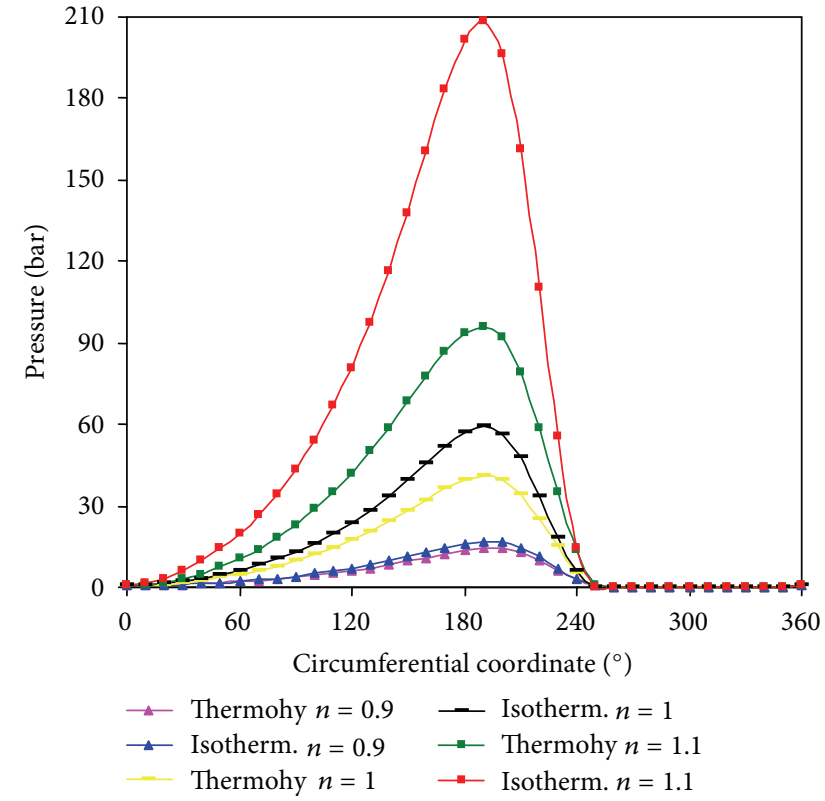

FIgURE 3: Pressure distributions versus the circumferential coordinate at the central plan of the journal bearing for different values of $n$ index. Comparison between isothermal and thermohydrodynamic cases.

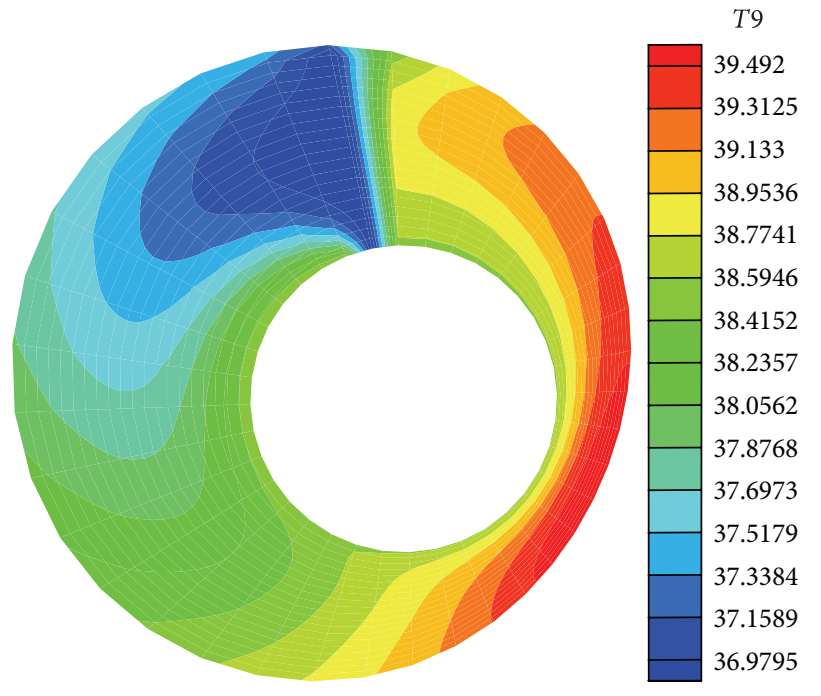

FIGURE 4: Isothermal lines of the journal bearing at its central plan for $N=1000 \mathrm{rev} . / \mathrm{min}$ and $n=0.9$.

This influence is more important for large value of this structure index $(n=1.1)$ where the difference of maximum temperature between the two cases $(N=1000 \mathrm{rev} . / \mathrm{min}$ and $N=3000 \mathrm{rev} . / \mathrm{min}$ ) is approximately $27^{\circ} \mathrm{C}$. This result can be explained by the viscosity evolution versus strain rate that is a power law of the structure index and the heat flux generated by shear in the film is more important in the case of bearings rotating at high speed.

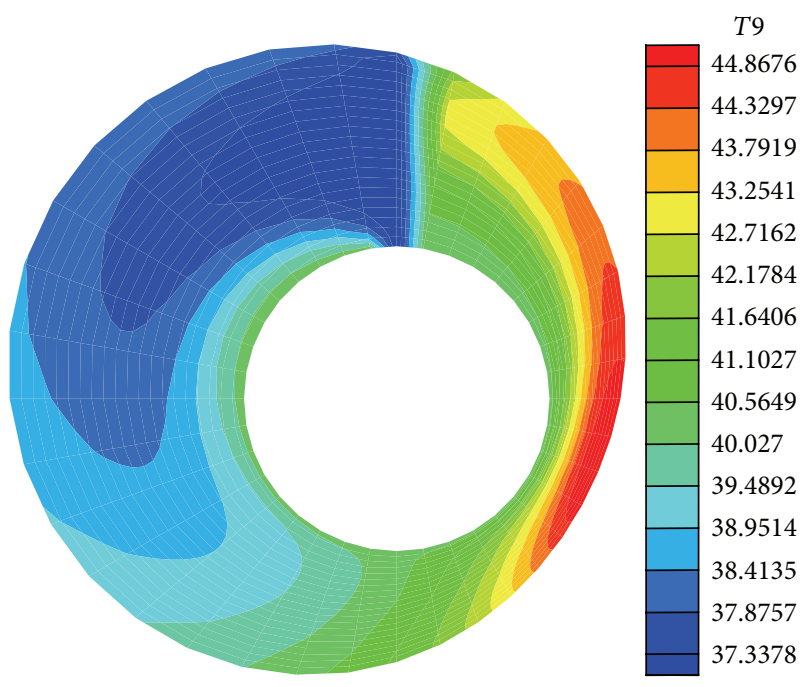

FIGURE 5: Isothermal lines of the journal bearing at its central plan for $N=3000 \mathrm{rev} . / \mathrm{min}$ and $n=0.9$.

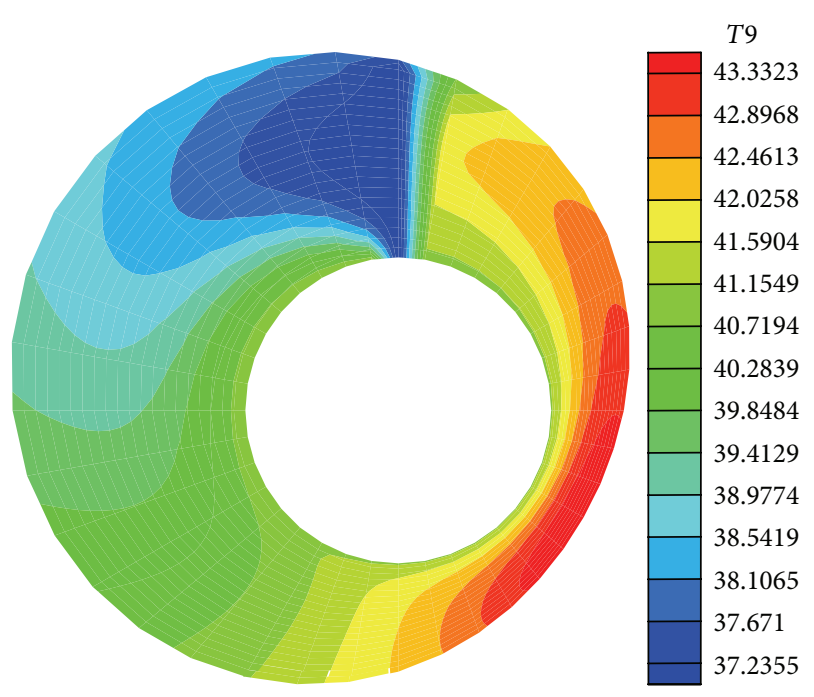

FIGURE 6: Isothermal lines of the journal bearing at its central plan for $N=1000 \mathrm{rev} . / \mathrm{min}$ and $n=1$.

Figures 10,11, 12, 13, 14, and 15 illustrate the influence of eccentricity and the structure index on the isothermal lines of the journal bearing. We can note that the isothermal lines are not affected by the eccentricity for small values of the structure index. This influence becomes important for large value of this structure index $(n=1.1)$ where the difference of maximum temperature between the two cases $(N=1000 \mathrm{rev} . / \mathrm{min}$ and $N=3000 \mathrm{rev} . / \mathrm{min})$ is approximately $27^{\circ} \mathrm{C}$.

Figures 16 and 17 represent the bearing and the film temperature evolutions, according to the circumferential coordinates and the film thickness, and for various values of index of structure $n$, where we can note that the temperature 


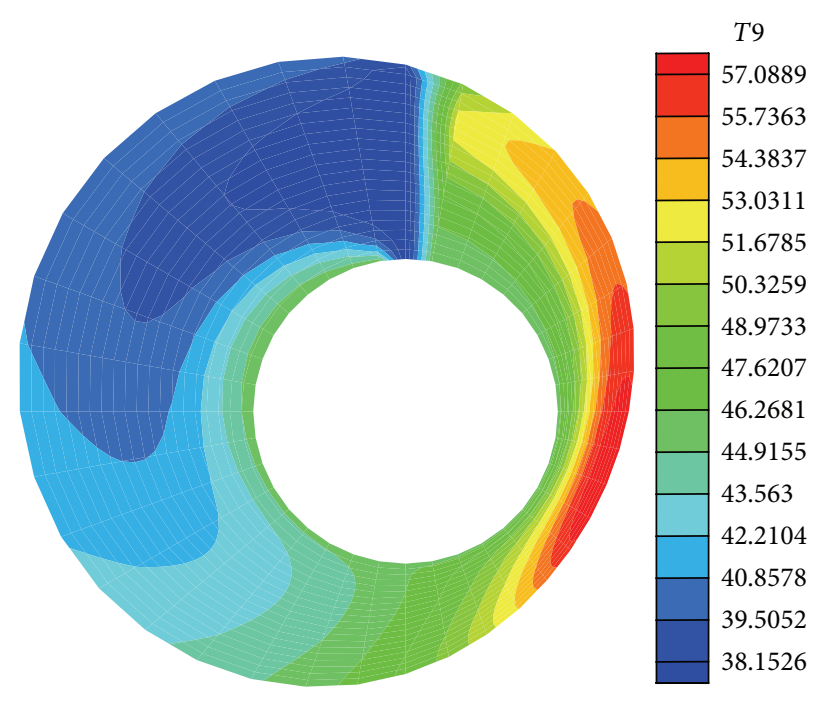

FIGURE 7: Isothermal lines of the journal bearing at its central plan for $N=3000 \mathrm{rev} . / \mathrm{min}$ and $n=1$.

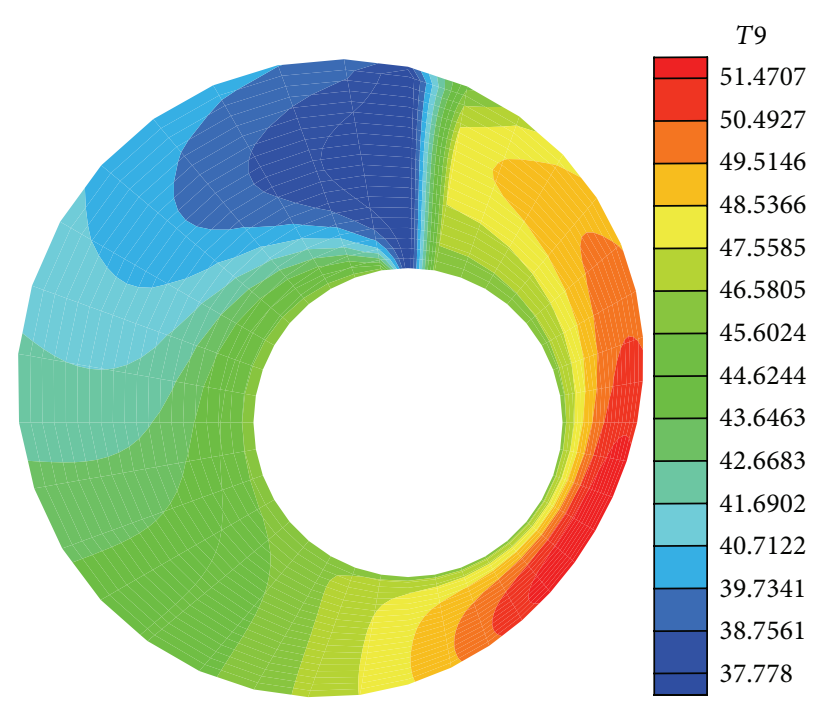

Figure 8: Isothermal lines of the journal bearing at its central plan for $N=1000 \mathrm{rev} . / \mathrm{min}$ and $n=1.1$.

of the film and the bearing increases with the increase of index $n$.

Figure 18 illustrates the comparison between the results obtained in this study and those of [11]. These results are related to the film temperature variation versus circumferential coordinate. As it is shown, good agreement is observed between all these results.

\section{Conclusions}

The work presented in this study is related to the journal bearings thermohydrodynamic lubrication aspect analysis

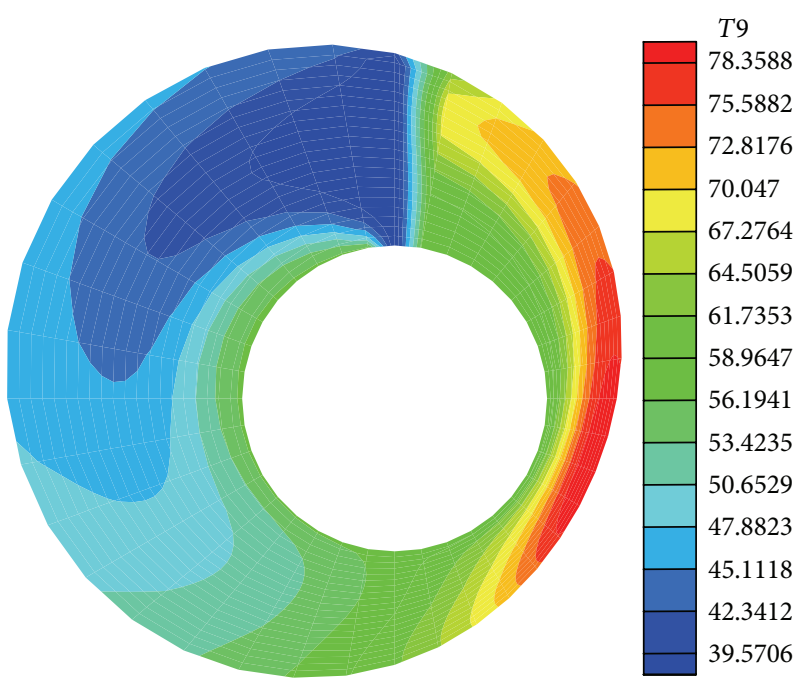

FIGURE 9: Isothermal lines of the journal bearing at its central plan for $N=3000 \mathrm{rev} . / \mathrm{min}$ and $n=1.1$.

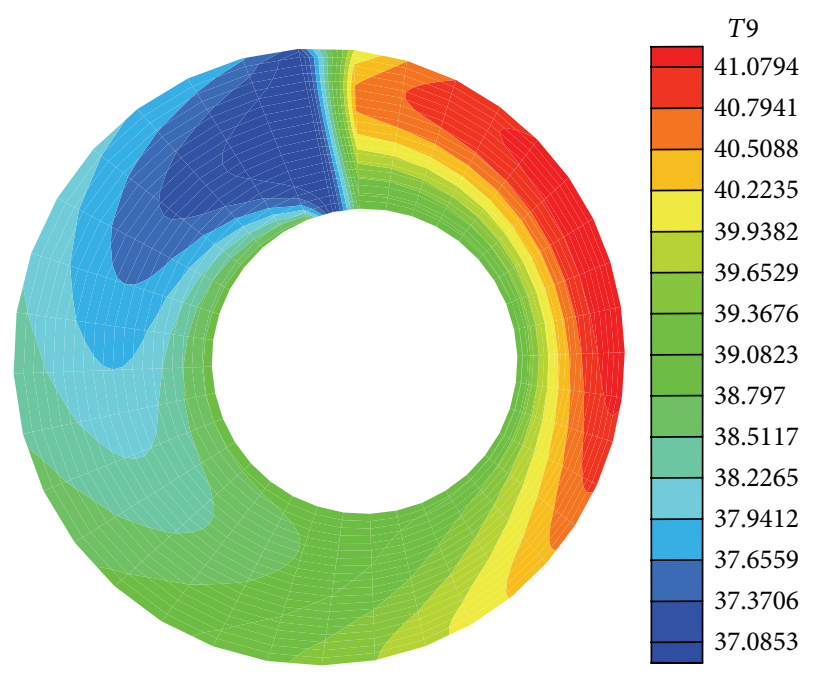

FIGURE 10: Isothermal lines of the journal bearing at its central plan for $\varepsilon=0.3$ and $n=0.9$.

using non-Newtonian fluids which are described by a powerlaw formula. The influence of the various values of the nonNewtonian power-law index, $n$, on the lubricant film (temperature, pressure) and the journal bearing properties is also analysed by using the Reynolds equation in its generalized form. Obtained results show the following.

(i) The increase of the structure index, $n$, generates an increase in the pressure. This increase becomes more significant for dilatant fluids case.

(ii) For the same operating conditions, the increase of index induces an increase in the pressure, the temperature, and the load. 


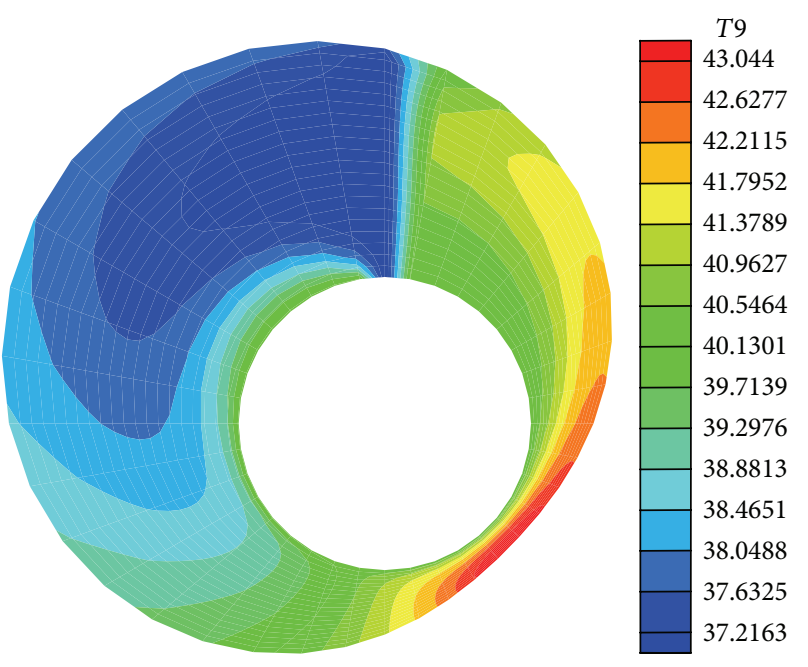

FIGURE 11: Isothermal lines of the journal bearing at its central plan for $\varepsilon=0.8$ and $n=0.9$.

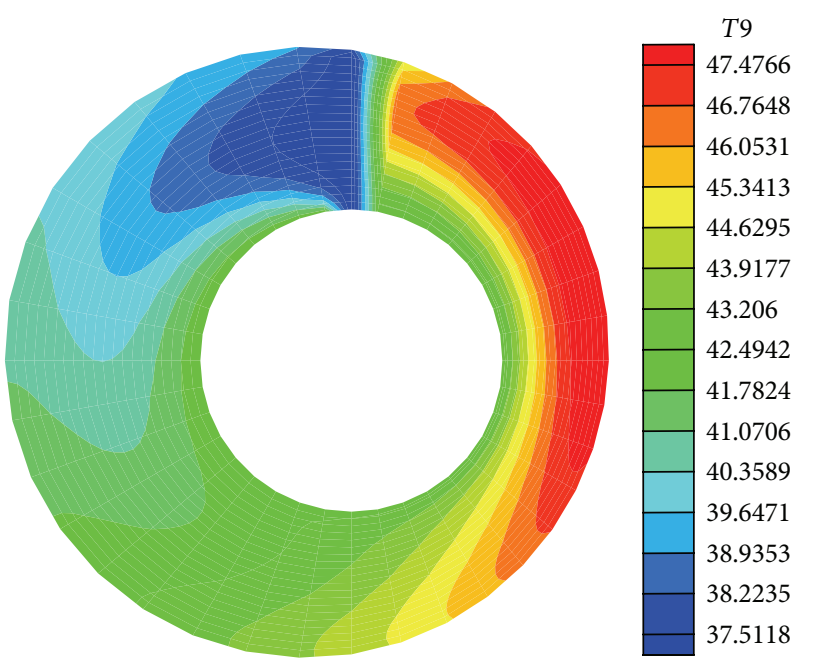

FIGURE 12: Isothermal lines of the journal bearing at its central plan for $\varepsilon=0.3$ and $n=1$.

(iii) For the dilatant fluids $(n>1)$, the load, the temperature, and the pressure are more significant than those of the Newtonian fluids.

(iv) For the pseudoplastic fluids $(n<1)$, the load, the temperature, and the pressure are weaker than those of the Newtonian fluids.

(v) The thermal effects are important in the dilatant fluids cases. The difference between obtained results by using isothermal theory of lubrication and nonisothermal one is very large (reached up to $116 \%$ ), which justifies the importance of the thermohydrodynamic study in the case of such fluids.

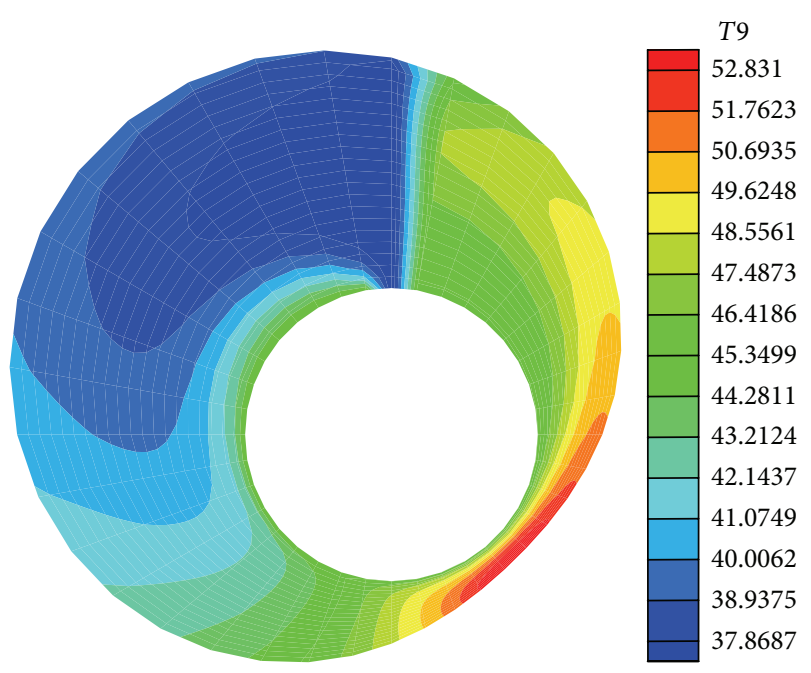

FIGURE 13: Isothermal lines of the journal bearing at its central plan for $\varepsilon=0.8$ and $n=1$.

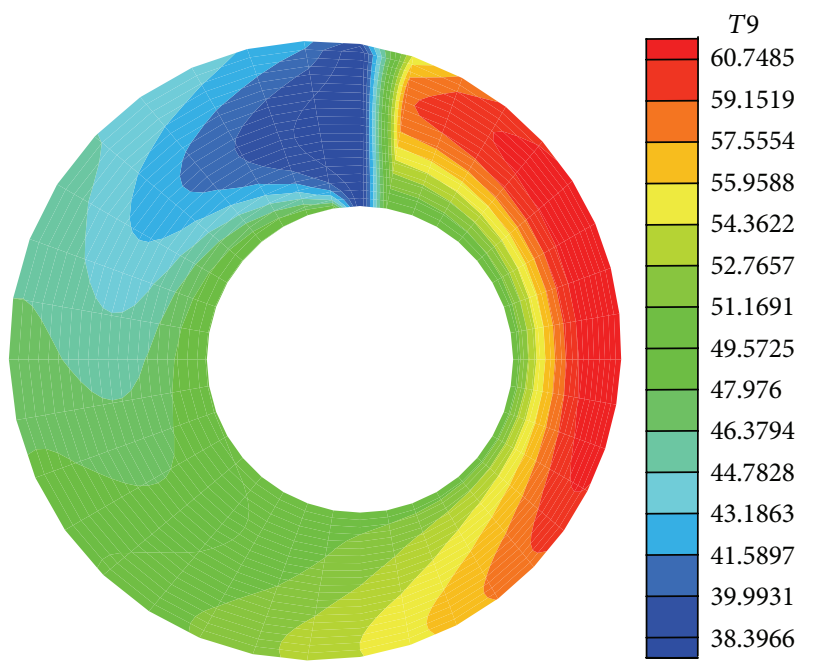

FIGURE 14: Isothermal lines of the journal bearing at its central plan for $\varepsilon=0.3$ and $n=1.1$.

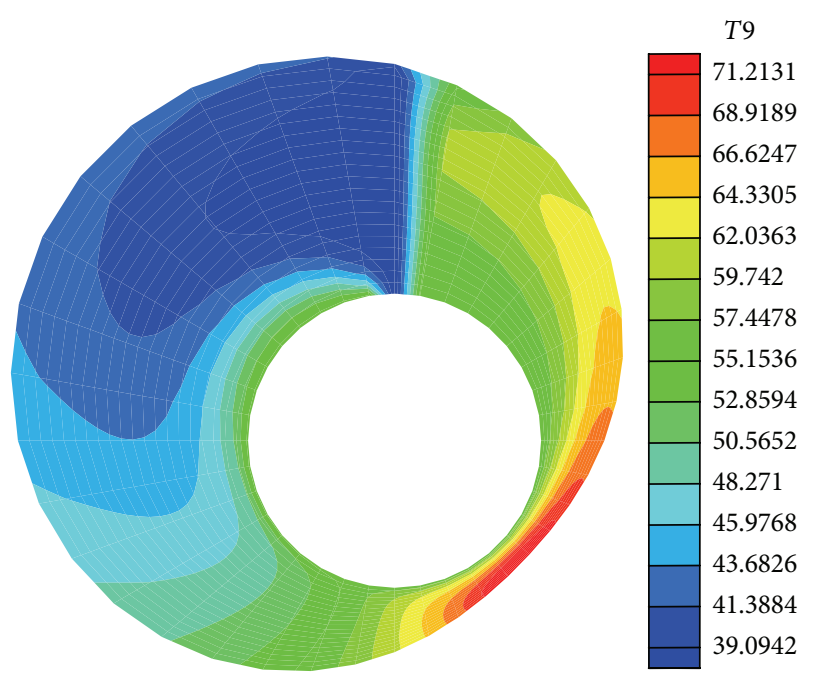

FIGURE 15: Isothermal lines of the journal bearing at its central plan for $\varepsilon=0.8$ and $n=1.1$. 


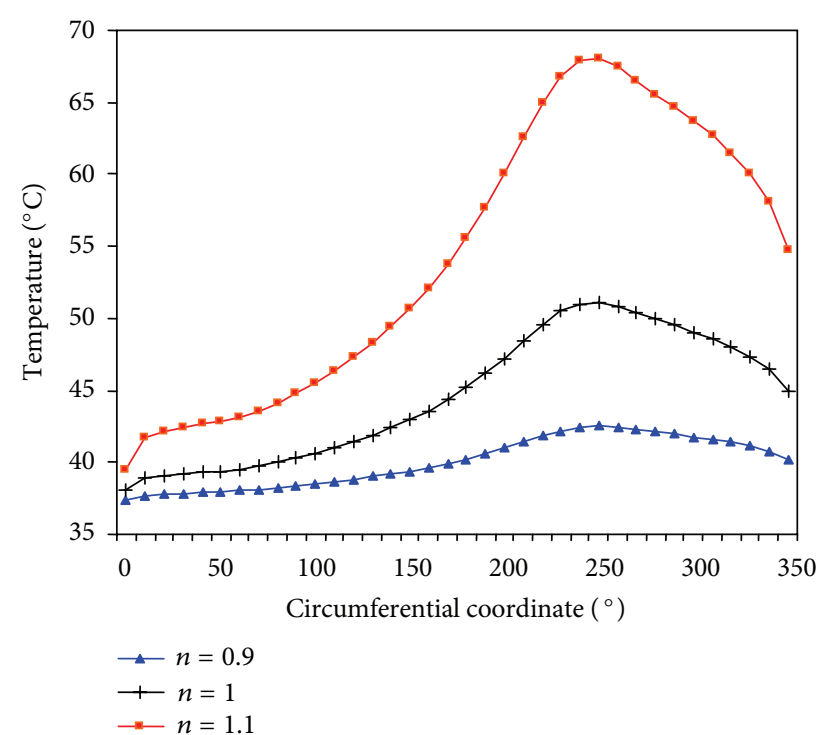

FIGURE 16: Evolution of the bearing internal surface temperature according to the circumferential coordinate at the central plan of the journal bearing and for different values of $n$.

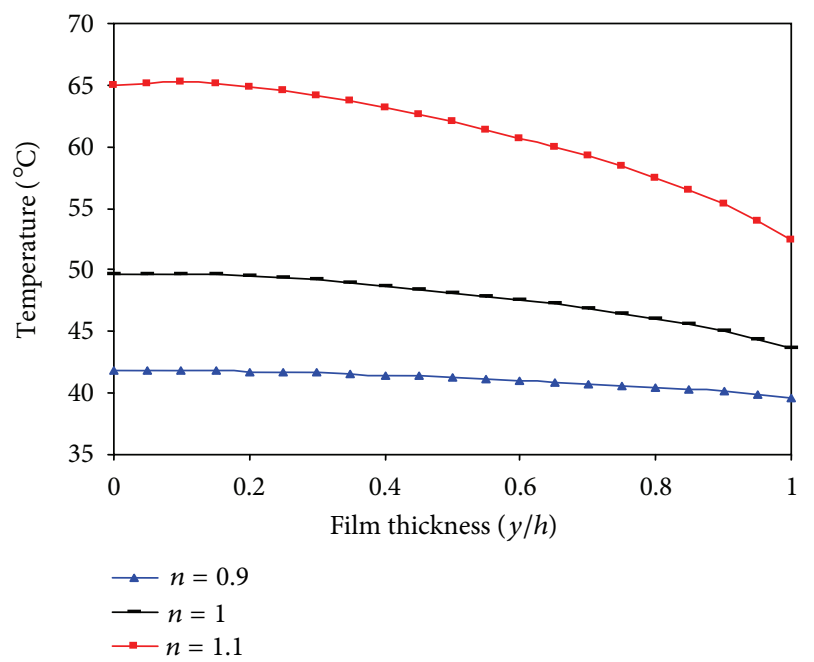

FigURE 17: Evolution of the lubricating film temperature according to its thickness at the central plan of the journal bearing and for different values of $n$.

(vi) The revolution number per minute has a slight influence on the isothermal lines for small values of the structure index. This influence is more important for large value of this index.

(vii) Good agreement is observed between the numerical results obtained in this study and those of [11].

\section{Nomenclature}

$l: \quad$ Length of the journal bearing, $\mathrm{m}$

$R_{S}: \quad$ Radius of the shaft, $\mathrm{m}$

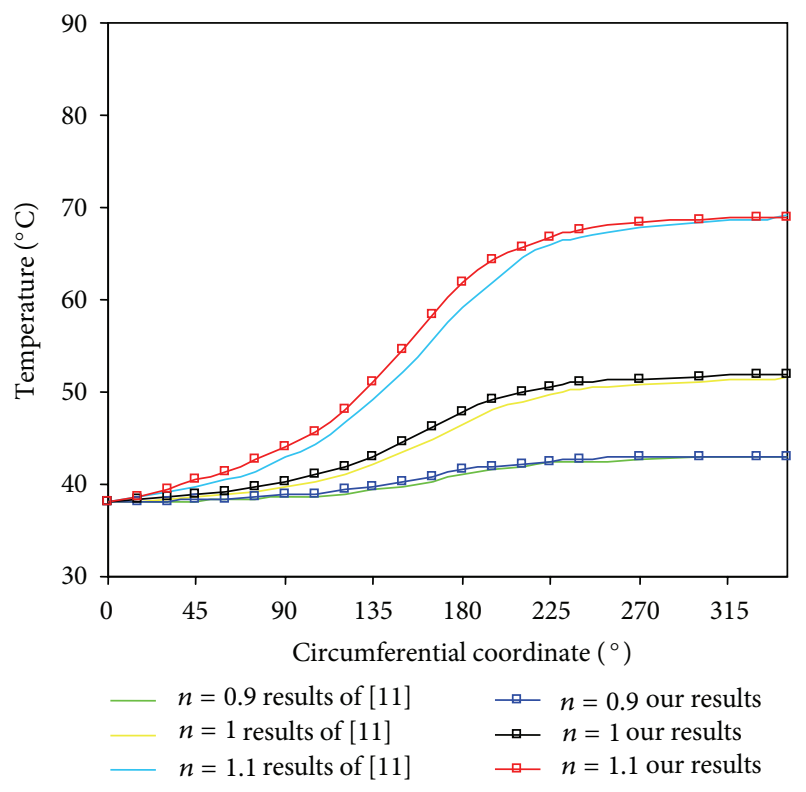

FIGURE 18: Film temperature variation versus the circumferential coordinate at the central plan of the journal bearing. Comparison between our results and those of [11].

$R_{B}: \quad$ Internal radius of the bearing, $\mathrm{m}$

$C: \quad$ Radial distance between shaft and bearing, $m$

$x, y, r, z: \quad$ Space coordinates, $\mathrm{m}$

$u, v, w: \quad$ Velocities, $\mathrm{m} / \mathrm{s}$

$T_{A}: \quad$ Ambient temperature, ${ }^{\circ} \mathrm{C}$

$P: \quad$ Pressure, $\mathrm{Pa}$

$\rho: \quad$ Density, $\mathrm{kg} / \mathrm{m}$

$C_{p}: \quad$ Specific heat, $\mathrm{J} / \mathrm{kg} \cdot \mathrm{K}$

$K_{B}: \quad$ Bearing thermal conductivity, $\mathrm{W} / \mathrm{m} \cdot \mathrm{K}$

$K_{S}: \quad$ Shaft thermal conductivity, $\mathrm{W} / \mathrm{m} \cdot \mathrm{K}$

$K_{F}: \quad \quad$ Film thermal conductivity, $\mathrm{W} / \mathrm{m} \cdot \mathrm{K}$

$h_{B}$ : Bearing convective heat transfer coefficient, $\mathrm{W} / \mathrm{m}^{2} \cdot \mathrm{K}$

$h_{S}$ : Shaft convective heat transfer coefficient, $\mathrm{W} / \mathrm{m}^{2} \cdot \mathrm{K}$.

\section{References}

[1] J. Frene, D. Nicolas, B. Degueurce, D. Berthe, and M. Godet, Lubrification Hydrodynamique, Paliers Et Butees, Lavoisier, Paris, France, 1990.

[2] A. Kingsbury, "Heat effects in lubricating films," Mechanical Engineering Journal, vol. 22, pp. 685-688, 1933.

[3] A. Harnoy, "An analysis of stress relaxation in elastico-viscous fluid lubrication of journal bearings," ASME Journal of lubrication Technology, vol. 100, no. 1, pp. 287-295, 1978.

[4] Z. S. Safar, "Journal bearings operating with non-newtonian lubricant films," Wear, vol. 53, no. 1, pp. 95-100, 1979.

[5] P. Sinha, J. B. Shukla, K. R. Prasad, and C. Singh, "Nonnewtonian power law fluid lubrication of lightly loaded cylinders with normal and rolling motion," Wear, vol. 89, no. 3, pp. 313-322, 1983.

[6] I. K. Dien and H. G. Elrod, "A generalized steady state Reynolds equation for non-Newtonian fluids, with application to journal 
bearing," Journal of Lubrication Technology, vol. 105, no. 3, pp. 385-390, 1983.

[7] P. D. Williams and G. R. Symmons, "Analysis of hydrodynamic journal bearings lubricated with non-Newtonian fluids," Tribology International, vol. 20, no. 3, pp. 119-124, 1987.

[8] P. D. Williams and G. R. Symmons, "Analysis of hydrodynamic slider thrust bearings lubricated with non-Newtonian fluids," Wear, vol. 117, no. 1, pp. 91-102, 1987.

[9] J. Y. Jang and C. C. Chang, "Adiabatic analysis of finite width journal bearings with non-Newtonian lubricants," Wear, vol. 122, no. 1, pp. 63-75, 1988.

[10] L. Tsann-Rong and L. Jen-Fin, "Compressible elastohydrodynamic lubrication of rolling and sliding contacts with a power law fluid," Wear, vol. 142, no. 2, pp. 315-330, 1991.

[11] J. Sheau-Ming and W. Cheng-I, “Thermohydrodynamic analysis of finite-width journal bearings with non-Newtonian lubricants," Wear, vol. 171, no. 1-2, pp. 41-49, 1994.

[12] M. Hlaváček, "A central film thickness formula for elastohydrodynamic lubrication of cylinders with soft incompressible coatings and a non-Newtonian piecewise power-law lubricant in steady rolling motion," Wear, vol. 205, no. 1-2, pp. 20-27, 1997.

[13] J. H. Kim and A. A. Seireg, "Thermohydrodynamic lubrication analysis incorporating Bingham rheological model," Journal of Tribology, vol. 122, no. 1, pp. 137-146, 2000.

[14] X. L. Wang, K. Q. Zhu, and S. Z. Wen, "Thermohydrodynamic analysis of journal bearings lubricated with couple stress fluids," Tribology International, vol. 34, no. 5, pp. 335-343, 2001.

[15] R. M. Manglik and P. Fang, "Thermal processing of viscous non-Newtonian fluids in annular ducts: effects of power-law rheology, duct eccentricity, and thermal boundary conditions," International Journal of Heat and Mass Transfer, vol. 45, no. 4, pp. 803-814, 2001.

[16] B. Fantino and B. Bou-Said, "Inertia, shear-thinning and thermal effects on connecting rod bearing behaviour," Tribology Series, no. 41, pp. 779-787, 2003.

[17] F. Bouyahia, M. Hajjam, M. El Khlifi, and D. Souchet, "Threedimensional non-Newtonian lubricants flows in sector-shaped, tilting-pads thrust bearings," Proceedings of the Institution of Mechanical Engineers, Part J, vol. 220, no. 4, pp. 375-384, 2006.

[18] X. L. Wang and K. Q. Zhu, "Numerical analysis of journal bearings lubricated with micropolar fluids including thermal and cavitating effects," Tribology International, vol. 39, no. 3, pp. 227-237, 2006.

[19] W. Wei, K. Liu, and M. Jiao, "Thermal and non-Newtonian analysis on mixed liquid-solid lubrication," Tribology International, vol. 40, pp. 1065-1074, 2007.

[20] H. C. Garg, V. Kumar, and H. B. Sharda, "Performance of slotentry hybrid journal bearings considering combined influences of thermal effects and non-Newtonian behavior of lubricant," Tribology International, vol. 43, no. 8, pp. 1518-1531, 2010.

[21] L. Jaw-Ren, C. Tsu-Liang, L. Long-Jin, and H. Tzu-Chen, "NonNewtonian dynamics characteristics of parabolic-film slider bearings: micropolar fluid model," Tribology International, vol. 48, pp. 226-231, 2012.

[22] B. Carnahan, Applied Numerical Methods, John Wiley \& Sons, New York, NY, USA, 1969. 

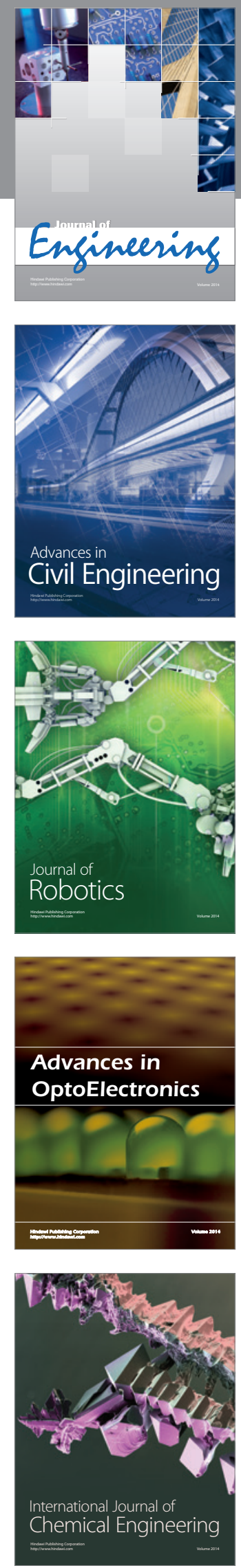

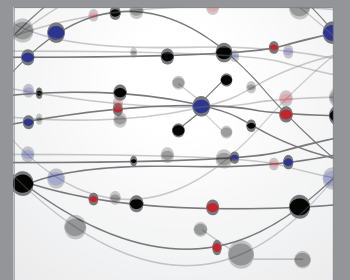

The Scientific World Journal
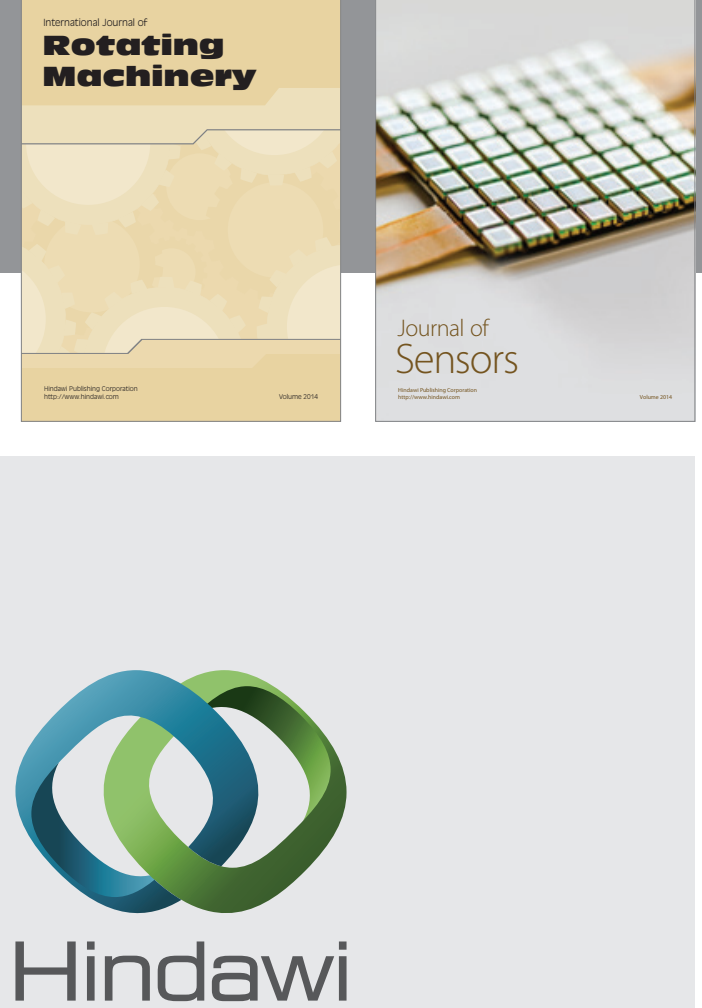

Submit your manuscripts at http://www.hindawi.com
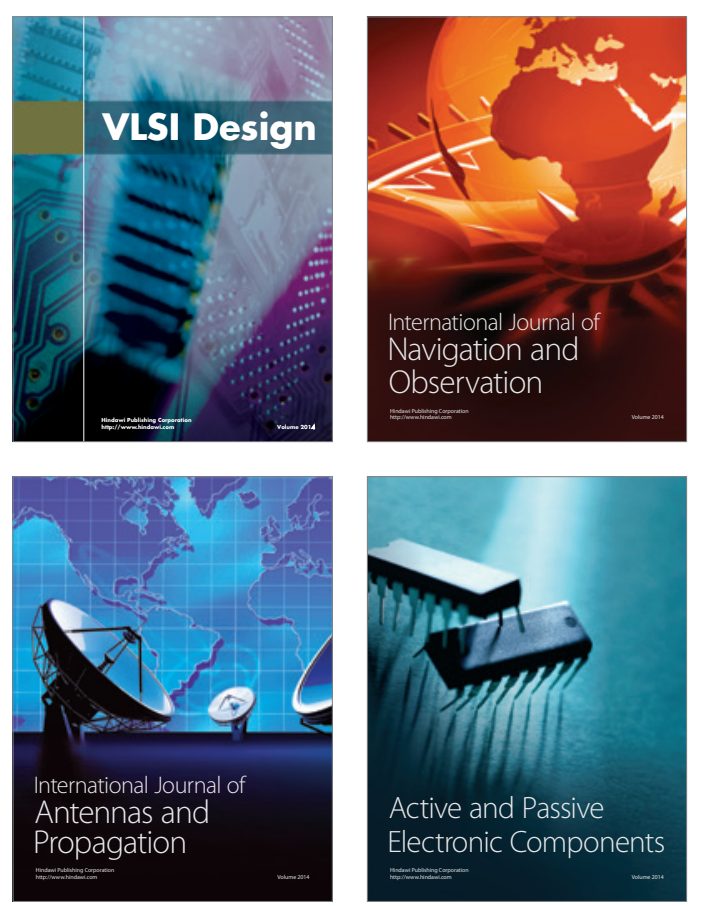
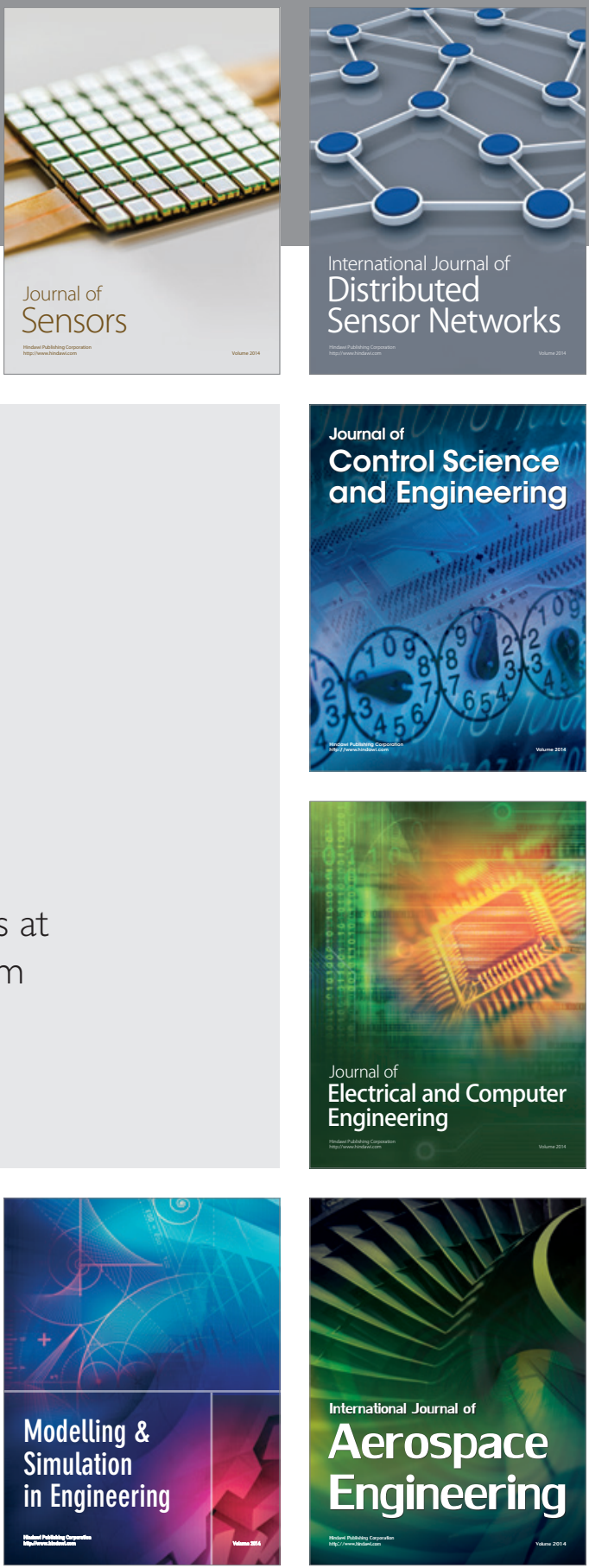

Journal of

Control Science

and Engineering
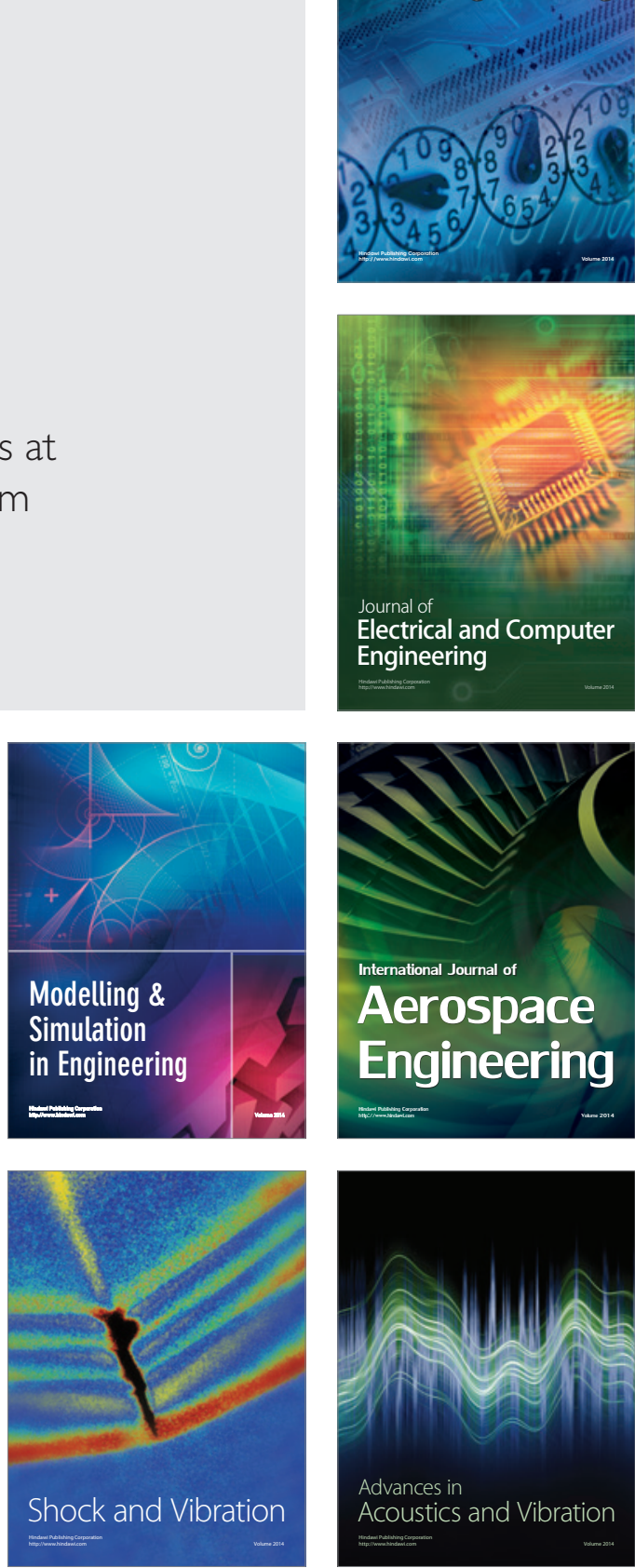